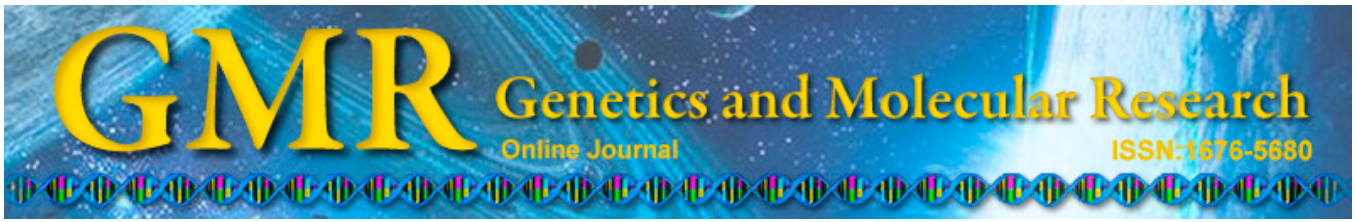

\title{
Single-nucleotide polymorphisms in dopamine receptor D1 are associated with heroin dependence but not impulsive behavior
}

\author{
J.H. Liu ${ }^{1 *}$, H.J. Zhong ${ }^{2 *}$, J. Dang ${ }^{2}$, L. Peng ${ }^{2}$ and Y.S. Zhu ${ }^{2,3}$ \\ ${ }^{1}$ College of Xinhua, Ningxia University, Yinchuan, China \\ ${ }^{2}$ Key Laboratory of Fertility Preservation and Maintenance, \\ Ningxia Medical University, Ministry of Education, Yinchuan, China \\ ${ }^{3}$ Department of Forensic Science, School of Medicine, Xi'an Jiaotong University, \\ Xi'an, China \\ *These authors contributed equally to this study. \\ Corresponding author: Y.S. Zhu \\ E-mail: zhuyongsheng3000@aliyun.com
}

Genet. Mol. Res. 14 (2): 4041-4050 (2015)

Received July 14, 2014

Accepted November 24, 2014

Published April 27, 2015

DOI http://dx.doi.org/10.4238/2015.April.27.19

\begin{abstract}
Previous studies suggested that dopamine receptors may be associated with drug dependence and impulsive behavior. In this study, we examined whether dopamine receptor D1 (DRD1) is associated with heroin dependence and the impulsive behavior in patients with heroin dependence. The participants included 367 patients with heroin dependence and 372 healthy controls from a Chinese Han population. We examined the potential association between heroin dependence and 8 single-nucleotide polymorphisms (rs686, rs4867798, rs1799914, rs4532, rs5326, rs265981, rs10078714, rs10078866) of DRD1, and the associations between single single-nucleotide polymorphism, haplotypes, and impulsive behavior. Compared with the healthy controls, heroin dependence patients showed a significantly lower frequency of GG homozygotes of rs5326 $(\mathrm{P}=0.027)$, significantly lower frequency of the $\mathrm{G}$ allele of $\operatorname{rs} 5326(\mathrm{P}=0.007$, odds ratio $=0.718$,
\end{abstract}


$95 \%$ confidence interval $=0.565-0.913$ ), and higher frequency of the rs $265981 \mathrm{G}$ allele $(\mathrm{P}=0.0002$, odds ratio $=1.711,95 \%$ confidence interval $=1.281-2.287)$. Furthermore, strong linkage disequilibrium was observed in 2 blocks ( $\left.\mathrm{D}^{\prime}>0.9\right)$. However, no association was observed between haplotypes and heroin dependence in the 2 blocks. This genetic behavior correlation study showed that the 2 singlenucleotide polymorphisms, rs5326 and rs265981, were not associated with the impulsive behavior in patients with heroin dependence. These findings indicate that $D R D 1$ gene polymorphisms are related to heroin dependence in a Chinese Han population and may be informative for future genetic or biological studies on heroin dependence.

Key words: Chinese population; Dopamine receptor D1; Heroin dependence; Single-nucleotide polymorphisms

\section{INTRODUCTION}

Heroin dependence is a chronic and relapsing brain disease characterized by drug dependence, tolerance, and compulsive seeking and use despite the harmful consequences (van den Bree et al., 1998). The relapse rate of heroin dependence is high because of its severe withdrawal symptoms, strong craving induction, and compulsive drug-seeking behavior after repeated use. Hence, preventing relapse of heroin dependence is very challenging. The genetic influence on the development of drug addiction has been shown to be substantial, with an estimated range of $40-60 \%$ for the inherited risk of drug addiction (Uhl, 2004; Uhl et al., 2008). The identification of vulnerability genes related to heroin dependence would be useful not only for understanding the pathogenesis of heroin dependence but also for preventing its occurrence and relapse.

Five dopamine receptors have been identified and characterized in humans. They are classified into 2 groups: D1-like (D1 and D5) and D2-like (D2, D3, and D4) (Le Foll et al., 2009). The dopamine receptor D1 (DRD1), a member of the dopamine receptor family, belongs to the G protein-coupled receptor superfamily and has 7 membrane-spanning domains (Civelli et al., 1991). DRD1 is involved in various brain functions, including motor control, attention symptoms, and reward and reinforcement mechanisms (Le Foll et al., 2009). DRD1 has also been shown to play an important role in heroin dependence (Gorwood et al., 2012). Administration of 2 DRD1 agonists, SKF 82958 and SKF 81297, produced a leftward shift in the heroin dose-response function in rhesus monkeys trained to self-administer heroin under a progressive-ratio schedule of reinforcement (Rowlett et al., 2007). In contrast, DRD1 blockade decreased heroin intake, but at a dose that produced nonspecific effects (Gerrits et al., 1994). Stimulation of DRD1 by opioid initiates a sequence of molecular events, including c-Fos (Liu et al., 1994), אFosB (Muller and Unterwald, 2005; Zachariou et al., 2006), extracellular receptor kinase (Borgkvist et al., 2008), and cAMP response element-binding (Dudman et al., 2003) activation, which shape neuron structure and functions (Nestler, 2004). Individual differences in impulsive behavior on a 5-choice task of sustained visual attention strongly predict individual variation in the rate of intravenous cocaine self-administration. Specifically, rats exhibiting trait impulsivity on the 5-choice serial reaction-time task showed a greater tendency for escalation of intravenous cocaine self-administration than did their non- 
impulsive counterparts. They also observed a significant inverse relationship between D2/3 receptor availability in the ventral striatum and trait impulsivity. These data demonstrated that trait impulsivity predicts drug reinforcement and that dopamine receptor dysfunction in abstinent drug addicts may be partly determined by premorbid factors (Dalley et al., 2007).

The $D R D 1$ gene is located at chromosome $5 \mathrm{q} 35.1$ and contains 2 exons separated by a small intron in the 5'-untranslated region (5'-UTR). Polymorphisms within or near $D R D 1$, particularly the DdeI polymorphism (rs4532), have been studied widely for their genetic association with other neuropsychiatric diseases (Wong et al., 2000). Although most polymorphisms failed to show an association, some polymorphisms have been shown to be significantly associated with bipolar disorders (Severino et al., 2005; Del Zompo et al., 2007), attention deficit hyperactivity disorder (Misener et al., 2004; Bobb et al., 2005), and alcoholism (Limosin et al., 2003; Kim et al., 2007). Although located in the 5'-UTR of DRD1, the rs4532 polymorphism can also affect $D R D 1$ expression. A preliminary pharmacogenetics study suggested that the rs4532 polymorphism is functionally important (Potkin et al., 2003). However, few studies have examined the association between the $D R D 1$ gene and opiate addiction. A study by Jacobs et al. (2013) found that polymorphisms in the DRD1 gene were associated with opiate addiction, despite significant differences in the racial makeup of individual samples. Another study found that $D R D 1$ gene rs5326 was associated with heroin dependence in African Americans, whereas the association was not significant after correction for multiple testing (Levran et al., 2009). These findings highlight the importance of determining the role of DRD1 in genetic predisposition to drug dependence.

In most previous studies, several important single-nucleotide polymorphisms (SNPs), includingrs 4867798 (5'-UTR), rs265981 (5'-UTR), rs10078714 (promoter), and rs10078866 (promoter), have not been studied, resulting in an ineffective capture of true causative SNPs in the $D R D 1$ gene because of the weak linkage disequilibrium between them. In the present study, to verify the putative association between DRD1 SNPs and heroin dependence, we investigated the association between 8 SNPs (rs686, rs4867798, rs1799914, rs4532, rs5326, rs265981, rs 10078714, and rs10078866) in the DRDl gene and the risk of heroin dependence in a Chinese Han population.

\section{MATERIAL AND METHODS}

\section{Subjects}

A hospital-based case-control study was conducted in 367 patients with heroin dependence (mean \pm standard deviation age: $39.6 \pm 5.6$ years) and 372 healthy controls (mean \pm standard deviation age: $40.3 \pm 4.5$ years). The patients were recruited from the Methadone Maintenance Treatment Program of the Xi' an Mental Health Center (Xi'an, China). Heroin dependence was diagnosed according to Diagnostic and Statistical Manual of Mental Disorders (DSM)-IV criteria, medical history, urine test results, and interview responses. A case vignette was prepared to assist with diagnosis, using a semi-structured interview with questions on a) age at initiation and duration of heroin use, b) quantity of drug used over this period, c) route of administration (nasal inhalation or injection), d) whether other substances were used or abused, and e) comorbidity for any other psychiatric disorder. Participants were excluded if they met the DSM-IV criteria for an additional Axis I disorder, had a history of alcohol, cigarette, or amphetamine use according to DSM-IV, were taking other prescribed medications 
that could affect the central nervous system, had a history of seizures, hematological diseases, or severe liver or kidney impairment, or were pregnant. Patients with heroin dependence and impulsive behavior were included if they met the following 3 criteria: impulsive behavior towards other people had occurred more than 3 times; the weighted total score of the modified overt aggression scale was more than 5 , and the item of the attack of physical strength was more than 1; the total score of the Barratt impulsivity scale-11 was more than 70 .

The unrelated healthy subjects were people who underwent health examinations in the First Hospital Affiliated to the Medical College of Xi'an Jiaotong University. Subjects who had substance abuse, participated in other studies, or suffered from chronic brain diseases were excluded. Written informed consent was obtained from all participants. The study protocol was approved by the Ethical Committee of Xi'an Mental Health Center.

\section{SNP selection}

The genomic sequence of the $D R D 1$ gene spans $8 \mathrm{~kb}$. Most previous studies only analyzed a few SNPs, which was insufficient to cover the gene locus. The present study selected a total of 8 genetic polymorphisms throughout the $D R D 1$ gene and the 5' and 3' flanking regions. The selected polymorphisms included SNPs that have been shown to be positively associated with nicotine dependence, heroin dependence, and alcoholism in previous studies (Kim et al., 2007; Batel et al., 2008; Gorwood et al., 2012; Peng et al., 2013) and most tag SNPs that were revealed by the genotype data of the Chinese Han population from the HapMap.

\section{Genotyping}

Genomic DNA was extracted from blood leukocytes using the EZNA ${ }^{\mathrm{TM}}$ Blood DNA Midi Kit (Omega Bio-Tek, Norcross, GA, USA) according to the manufacturer protocol. Cases and controls were mixed on the same plates, and a double-blind procedure was performed. Genotyping was carried out for all SNPs using the MassARRAY platform (Sequenom, San Diego, CA, USA). Briefly, SNPs were genotyped using high-throughput matrix-assisted laser desorption ionization time-of-flight mass spectrometry. The resulting spectra were processed using the Typer Analyzer software (Sequenom) and genotype data were generated for the samples. The final genotype call rate of each SNP was $>98 \%$ and the overall genotyping call rate was $98.6 \%$, indicating the reliability of the data for further statistical analysis.

\section{Statistical analysis}

All statistical tests were conducted using SPSS 16.0 for Windows (SPSS Inc., Chicago, IL, USA). Hardy-Weinberg equilibrium for each SNP was assessed using GENEPOP v4.0 (Rousset and Raymond, 1995). Associations between the case-control status and each polymorphism were assessed using the Fisher exact test or Pearson chi-square test. Unconditional logistic regression was used to calculate the odds ratio (OR) and 95\% confidence interval (CI) of the independent association between each locus and the presence of heroin dependence. Haplotype blocks were defined according to the criteria developed by Gabriel et al. (2002). Pair-wise linkage disequilibrium (LD) statistics ( $\mathrm{D}^{\prime}$ and $\mathrm{r}^{2}$ ) and haplotype frequency were calculated, and haplotype blocks were constructed using the Haploview 4.0 (Barrett et al., 2005). To ensure that the LD blocks most closely reflected the population level LD patterns, blocks 
were defined based on the control samples alone. Bonferroni's correction was used to adjust the test level when multiple comparisons were conducted, and the $\mathrm{P}$ value was divided by the total number of loci or haplotypes.

\section{RESULTS}

More than $99 \%$ of the samples were genotyped successfully for each SNP, and the replicate experiment for 40 randomly selected samples (5.41\%) showed completely consistent genotype data with the original analysis. No significant deviation from Hardy-Weinberg equilibrium was observed for any of the SNPs in the controls and patients with heroin dependence. The analyses of LD of the patient and control groups revealed that 6 SNPs (rs4867798, rs686, rs 1799914, rs4532, rs5326, rs265981) and 2 SNPs (rs10078714, rs10078866) were located in haplotype block 1 and block $2\left(\mathrm{D}^{\prime}>0.9\right.$, Figure $1 ; \mathrm{r}^{2}>0.8$, Figure 2$)$, respectively. The genotype distributions, allelic frequencies, and haplotypes in the control and patient groupsas well as the results of statistical analysis are provided in Tables 1-4.

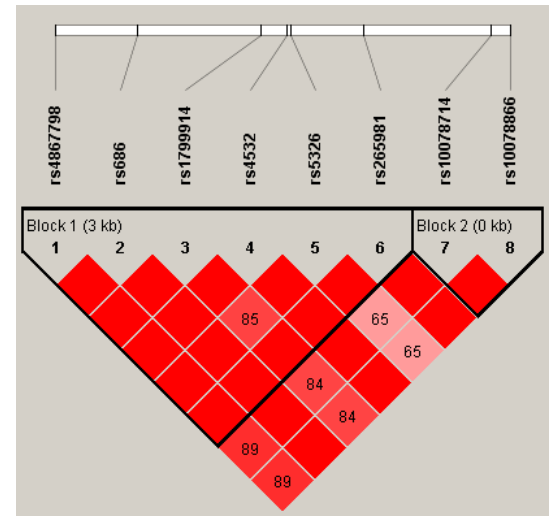

Figure 1. Linkage disequilibrium plot of the 8 SNPs in the DRDl gene. Values in squares are the pairwise calculation of $\mathrm{D}^{\prime}$.

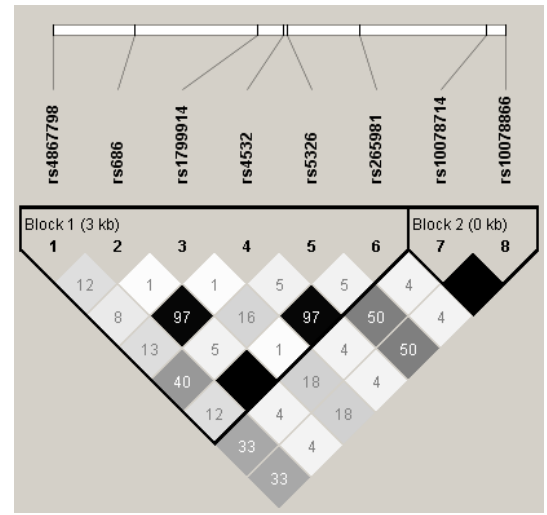

Figure 2. Linkage disequilibrium plot of the 8 SNPs in the DRDI gene. Values in squares are the pairwise calculation of $\mathrm{r}^{2}$. 
J.H. Liu et al.

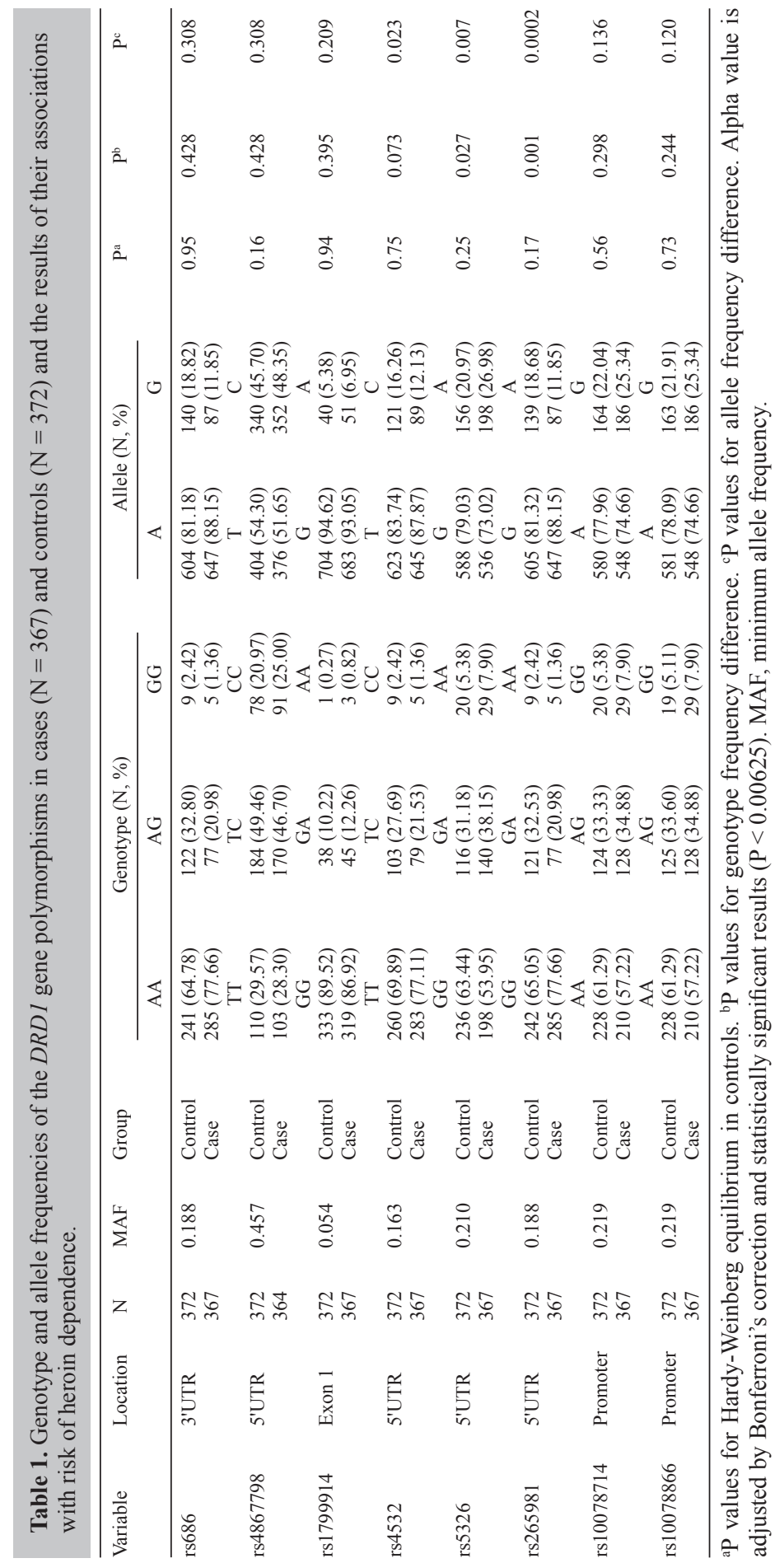


Table 2. DRD1 haplotype in block 1 frequencies and the results of their associations with risk of heroin dependence.

\begin{tabular}{|c|c|c|c|c|c|c|c|c|c|}
\hline \multirow[t]{2}{*}{ Haplotype $^{a}$} & \multicolumn{6}{|c|}{ ID } & \multicolumn{2}{|c|}{ Gene-counting (frequency ${ }^{\mathrm{b}} \%$ ) } & \multirow[t]{2}{*}{$P$ value } \\
\hline & rs4867798 & rs686 & rs1799914 & rs 4532 & rs5326 & rs 265981 & Cases & Controls & \\
\hline HAP1 & $\mathrm{T}$ & A & G & $\mathrm{T}$ & G & G & 146.4 & 134.3 & 0.305 \\
\hline HAP2 & $\mathrm{C}$ & A & G & $\mathrm{T}$ & G & G & 75.6 & 89.7 & 0.256 \\
\hline HAP3 & $\mathrm{T}$ & G & G & $\mathrm{C}$ & G & A & 43.7 & 60.6 & 0.086 \\
\hline HAP4 & $\mathrm{C}$ & A & G & $\mathrm{T}$ & A & G & 76.0 & 58.0 & 0.071 \\
\hline
\end{tabular}

${ }^{a}$ Haplotypes with frequency $<0.05$ were excluded. ${ }^{b}$ Based on comparison of frequency distribution of all haplotypes for the combination of SNPs. 'Alpha value is adjusted by Bonferroni's correction and statistically significant results $(\mathrm{P}<0.008)$

Table 3. DRD1 haplotype in block 2 frequencies and the results of their associations with risk of heroin dependence.

\begin{tabular}{|c|c|c|c|c|c|}
\hline \multirow[t]{2}{*}{ Haplotype } & \multicolumn{2}{|c|}{ ID } & \multicolumn{2}{|c|}{ Gene-counting (frequency \%) } & \multirow[t]{2}{*}{$P$ value } \\
\hline & rs10078714 & rs10078866 & Cases & Controls & \\
\hline HAP1 & A & A & 274.1 & 290.5 & 0.283 \\
\hline HAP2 & G & G & 92.9 & 81.5 & 0.283 \\
\hline
\end{tabular}

${ }^{a}$ Based on comparison of frequency distribution of all haplotypes for the combination of SNPs. ${ }^{\mathrm{b}}$ Alpha value is adjusted by Bonferroni's correction and statistically significant results $(\mathrm{P}<0.025)$.

Table 4. Impulsive behavior association with genotypes rs5326 and rs265981.

\begin{tabular}{|c|c|c|c|c|c|c|}
\hline \multirow[t]{2}{*}{ Variable } & \multicolumn{2}{|c|}{ High-impulsive } & \multicolumn{2}{|c|}{ Low-impulsive } & \multirow[t]{2}{*}{ P value ${ }^{a}$} & \multirow[t]{2}{*}{ OR, $95 \%$ CI } \\
\hline & $\mathrm{N}$ & $\%$ & $\mathrm{~N}$ & $\%$ & & \\
\hline \multicolumn{7}{|l|}{ rs5326 } \\
\hline GG & 59 & 57.3 & 139 & 84.8 & \multirow[t]{2}{*}{0.424} & \multirow[t]{2}{*}{$1.206,0.762-1.908$} \\
\hline $\mathrm{GA}+\mathrm{AA}$ & 44 & 42.7 & 125 & 15.2 & & \\
\hline \multicolumn{7}{|l|}{ rs265981 } \\
\hline GG & 57 & 74.0 & 228 & 78.6 & \multirow[t]{2}{*}{0.390} & \multirow[t]{2}{*}{$0.775,0.433-1.386$} \\
\hline $\mathrm{GA}+\mathrm{AA}$ & 20 & 26.0 & 62 & 21.4 & & \\
\hline
\end{tabular}

Compared with the healthy controls, patients with heroin dependence had a significantly lower frequency of GG homozygotes of rs5326 $(\mathrm{P}=0.027)$, a significantly lower frequency of the $\mathrm{G}$ allele of $\mathrm{rs} 5326(\mathrm{P}=0.007, \mathrm{OR}=0.718,95 \% \mathrm{CI}=0.565-0.913)$, and a higher frequency of the $\mathrm{rs} 265981 \mathrm{G}$ allele $(\mathrm{P}=0.0002, \mathrm{OR}=1.711,95 \% \mathrm{CI}=1.281-2.287)$. The rs5326 showed a nominal significant $\mathrm{P}$-value for association $(\mathrm{P}<0.05)$, but did not pass the threshold value $(\mathrm{P}<0.00625)$. Strong LD was observed in the 2 blocks $\left(\mathrm{D}^{\prime}>0.9\right)$. However, we observed no association between haplotype and heroin dependence in the 2 blocks. The genetic behavior correlation study showed that 2 SNPs, rs5326 and rs265981, were not associated with impulsive behavior of the patients with heroin dependence.

\section{DISCUSSION}

Drug-induced persistent neuroadaptation in reward-related learning and memory processes, which leads to hypersensitivity to drug-associated cues, impulsive decision-making, and abnormal learned behaviors, is the neurobiological basis for the transition to dependence 
(Nestler, 2004; Kauer and Malenka, 2007). Postmortem analysis revealed the regulatory effects of $D R D 1$ variation on its mRNA expression in the striatum, which were blunted by chronic opioid abuse (Kauer and Malenka, 2007). Our results demonstrate that a genetic change in DRD1 is linked to heroin dependence in humans, and extends the list of variants that may affect the development of heroin dependence (Jacobs et al., 2013; Peng et al., 2013).

Several studies have reported that $D R D 1$ gene polymorphisms are associated with alcohol dependence (Limosin et al., 2003; Kim et al., 2007; Batel et al., 2008), nicotine dependence (Vink et al., 2006; Huang et al., 2008; Levran et al., 2009), nicotine metabolite ratio (Lee et al., 2012), stimulant dependence (Liu et al., 2006), and a series of addictive behaviors (Comings et al., 1997). This may be because DRD1 plays different roles in the dependence to different drugs or because of population differences. A previous study found that DRD1 gene rs5326 was associated with heroin dependence in African Americans (Levran et al., 2009). However, the association was not significant after correction for multiple testing (Levran et al., 2009). In this study, significant differences were found in the distribution of genotype and allele frequencies in DRD1 gene rs5326 between heroin-dependent subjects and healthy controls, and the rs5326 polymorphism showed a nominal significant $\mathrm{P}$-value for association $(\mathrm{P}<$ $0.05)$, but did not pass the threshold value $(\mathrm{P}<0.00625)$. Among patients with heroin dependence, subjects with rs5326 CC genotypes developed heroin dependence more rapidly than those without rs5326 CC genotypes (Peng et al., 2013). The results indicated that DRD1 gene polymorphisms may not be important in the susceptibility to heroin dependence in the Chinese Han population, but may be associated with the rapidity of heroin dependence development from first drug use. These DRDI gene variations can change the mRNA secondary structure, which may affect the stability, processing, or subcellular targeting of the mRNA transcript and thereby alter splicing, transcription, and translation efficiency (Ramos et al., 2004). In this case-control association study, the $\mathrm{G}$ alleles of rs 265981 were strongly associated with an increased risk of heroin dependence. This is the first report to identify a significant association between $D R D 1$ gene rs265981 and heroin dependence. In previous studies, DRD1 polymorphisms have also been shown to be associated with substance dependence (Kim et al., 2007; Huang et al., 2008), addictive behavior (da Silva Lobo et al., 2007), and psychiatric diseases (Hettinger et al., 2008; Zhu et al., 2011). In this study, 2 SNPs (rs4532, rs686) were not associated with heroin dependence. These differences may be correlated to alterations in hormone levels, neuronal system adaptations, the pharmacokinetics of substances of abuse (Russo et al., 2003), or differences in ethnic groups. To some extent, this finding further supports a role of $D R D 1$ polymorphism in drug dependence.

In conclusion, these findings will be useful for future studies aimed at identifying functional polymorphisms within or close to the $D R D 1$ gene using a systemic approach in a larger sample set. Our results agree with the dopamine hypothesis developed to understand the chronic effects of heroin on the brain. This study increases the understanding of the neurobiological mechanisms of heroin and may be used to develop better treatment strategies against heroin dependence.

\section{ACKNOLWEDGMENTS}

Research supported by the Ningxia Autonomous Region Natural Sciences Fund Project (\#Nz12169) and the National Science Foundation of China (\#NSFC31100900). The funding sources provided input into the design of this study, the collection, analysis, and interpretation 
of data, the writing of the report, and the decision to submit the paper for publication.

\section{REFERENCES}

Barrett JC, Fry B, Maller J and Daly MJ (2005). Haploview: analysis and visualization of LD and haplotype maps. Bioinformatics 21: 263-265.

Batel P, Houchi H, Daoust M, Ramoz N, et al. (2008). A haplotype of the DRD1 gene is associated with alcohol dependence. Alcohol Clin. Exp. Res. 32: 567-572.

Bobb AJ, Addington AM, Sidransky E, Gornick MC, et al. (2005). Support for association between ADHD and two candidate genes: NET1 and DRD1. Am. J. Med. Genet. B. Neuropsychiatr. Genet. 134B: 67-72.

Borgkvist A, Valjent E, Santini E, Herve D, et al. (2008). Delayed, context- and dopamine D1 receptor-dependent activation of ERK in morphine-sensitized mice. Neuropharmacology 55: 230-237.

Civelli O, Bunzow JR, Grandy DK, Zhou QY, et al. (1991). Molecular biology of the dopamine receptors. Eur. J. Pharmacol. 207: 277-286.

Comings DE, Gade R, Wu S, Chiu C, et al. (1997). Studies of the potential role of the dopamine D1 receptor gene in addictive behaviors. Mol. Psychiatr. 2: 44-56.

da Silva Lobo DS, Vallada HP, Knight J, Martins SS, et al. (2007). Dopamine genes and pathological gambling in discordant sib-pairs. J. Gambl. Stud. 23: 421-433.

Dalley JW, Fryer TD, Brichard L, Robinson ES, et al. (2007). Nucleus accumbens D2/3 receptors predict trait impulsivity and cocaine reinforcement. Science 315: 1267-1270.

Del Zompo M, De Luca V, Severino G, Ni X, et al. (2007). Haplotype association study between DRD1 gene and bipolar type I affective disorder in two samples from Canada and Sardinia. Am. J. Med. Genet. B Neuropsychiatr. Genet. 144B: 237-241.

Dudman JT, Eaton ME, Rajadhyaksha A, Macias W, et al. (2003). Dopamine D1 receptors mediate CREB phosphorylation via phosphorylation of the NMDA receptor at Ser 897-NR1. J. Neurochem. 87: 922-934.

Gabriel SB, Schaffner SF, Nguyen H, Moore JM, et al. (2002). The structure of haplotype blocks in the human genome. Science 296: 2225-2229.

Gerrits MA, Ramsey NF, Wolterink G and van Ree JM (1994). Lack of evidence for an involvement of nucleus accumbens dopamine D1 receptors in the initiation of heroin self-administration in the rat. Psychopharmacology 114: 486-494.

Gorwood P, Le Strat Y, Ramoz N, Dubertret C, et al. (2012). Genetics of dopamine receptors and drug addiction. Hum. Genet. 131: 803-822.

Hettinger JA, Liu X, Schwartz CE, Michaelis RC, et al. (2008). A DRD1 haplotype is associated with risk for autism spectrum disorders in male-only affected sib-pair families. Am. J. Med. Genet. B Neuropsychiatr. Genet. 147B: 628-636.

Huang W, Ma JZ, Payne TJ, Beuten J, et al. (2008). Significant association of DRD1 with nicotine dependence. Hum. Genet. 123: 133-140.

Jacobs MM, Okvist A, Horvath M, Keller E, et al. (2013). Dopamine receptor D1 and postsynaptic density gene variants associate with opiate abuse and striatal expression levels. Mol.Psychiatr. 18: 1205-1210.

Kauer JA and Malenka RC (2007). Synaptic plasticity and addiction. Nat. Rev. Neurosci. 8: 844-858.

Kim DJ, Park BL, Yoon S, Lee HK, et al. (2007). 5' UTR polymorphism of dopamine receptor D1 (DRD1) associated with severity and temperament of alcoholism. Biochem. Biophys. Res.Commun. 357: 1135-1141.

Le Foll B, Gallo A, Le Strat Y, Lu L, et al. (2009). Genetics of dopamine receptors and drug addiction: a comprehensive review. Behav. Pharmacol. 20: 1-17.

Lee W, Ray R, Bergen AW, Swan GE, et al. (2012). DRD1 associations with smoking abstinence across slow and normal nicotine metabolizers. Pharmacogenet. Genom. 22: 551-554.

Levran O, Londono D, O’Hara K, Randesi M, et al. (2009). Heroin addiction in African Americans: a hypothesis-driven association study. Genes Brain Behav. 8: 531-540.

Limosin F, Loze JY, Rouillon F, Ades J, et al. (2003). Association between dopamine receptor D1 gene DdeI polymorphism and sensation seeking inalcohol-dependent men. Alcohol Clin. Exp. Res. 27: 1226-1228.

Liu HC, Chen CK, Leu SJ, Wu HT, et al. (2006). Association between dopamine receptor D1 A-48G polymorphism and methamphetamine abuse. Psychiatry Clin. Neurosci. 60: 226-231.

Liu J, Nickolenko J and Sharp FR (1994). Morphine induces c-fos and junB in striatum and nucleus accumbens via D1 and N-methyl-D-aspartate receptors. Proc. Natl. Acad. Sci. U. S. A. 91: 8537-8541.

Misener VL, Luca P, Azeke O, Crosbie J, et al. (2004). Linkage of the dopamine receptor D1 gene to attention-deficit/ hyperactivity disorder. Mol. Psychiatr. 9: 500-509. 
Muller DL and Unterwald EM (2005). D1 dopamine receptors modulate deltaFosB induction in rat striatum after intermittent morphine administration. J. Pharmacol. Exp.Ther. 314: 148-154.

Nestler EJ (2004). Molecular mechanisms of drug addiction. Neuropharmacology 47 (Suppl 1): 24-32.

Peng S, Du J, Jiang H, Fu Y, et al. (2013). The dopamine receptor D1 gene isassociated with the length of interval between first heroin use and onset of dependence in Chinese Han heroin addicts. J. Neural. Transm. 120: 1591-1598.

Potkin SG, Basile VS, Jin Y, Masellis M, et al. (2003). D1 receptor alleles predict PET metabolic correlates of clinical response to clozapine. Mol. Psychiatr. 8: 109-113.

Ramos M, Goni-Allo B and Aguirre N (2004). Studies on the role of dopamine D1 receptors in the development and expression of MDMA-induced behavioral sensitization in rats. Psychopharmacology 177: 100-110.

Rousset F and Raymond M (1995). Testing heterozygote excess and deficiency. Genetics 140: 1413-1419.

Rowlett JK, Platt DM, Yao WD and Spealman RD (2007). Modulation of heroin and cocaine self-administration by dopamine D1- and D2-like receptor agonists in rhesus monkeys. J. Pharmacol. Exp. Ther. 321: 1135-1143.

Russo SJ, Festa ED, Fabian SJ, Gazi FM, et al. (2003). Gonadal hormones differentially modulate cocaine-induced conditioned place preference in male and female rats. Neuroscience 120: 523-533.

Severino G, Congiu D, Serreli C, De Lisa R, et al. (2005). A48G polymorphism in the D1 receptor genes associated with bipolar I disorder. Am. J. Med. Genet. B Neuropsychiatr. Genet. 134B: 37-38.

Uhl GR (2004). Molecular genetics of substance abuse vulnerability: remarkable recent convergence of genome scan results. Ann. N Y Acad. Sci. 1025: 1-13.

Uhl GR, Drgon T, Johnson C, Fatusin OO, et al. (2008). "Higher order”' addiction molecular genetics: convergent data from genome-wide association in humans and mice. Pharmacol. Res. 75: 98-111.

van den Bree MB, Johnson EO, Neale MC and Pickens RW (1998). Genetic and environmental influences on drug use and abuse/dependence in male and female twins. Drug Alcohol Depend. 52: 231-241.

Vink JM, Posthuma D, Neale MC, ElineSlagboom P, et al. (2006). Genome-wide linkage scan to identify loci for age at first cigarette in Dutch sibling pairs. Behav. Genet. 36: 100-111.

Wong AH, Buckle CE and Van Tol HH (2000). Polymorphisms in dopamine receptors: what do they tell us? Eur. J. Pharmacol. 410: 183-203.

Zachariou V, Bolanos CA, Selley DE, Theobald D, et al. (2006). An essential role for DeltaFosB in the nucleus accumbens in morphine action. Nat. Neurosci. 9: 205-211.

Zhu F, Yan CX, Wang Q, Zhu YS, et al. (2011). An association study between dopamine D1 receptor gene polymorphisms and the risk of schizophrenia. Brain Res. 1420: 106-113. 